Thorax, 1978, 33, 253-256

\title{
Blood flow and pressure measurements of right coronary artery to left ventricle fistula
}

\author{
ISSEI KISO, TOYOHIKO ITOH, MIKITO MORISHITA, KAZUAKI KATO, AND \\ YOSHIYA ISHIKURA
}

From the Departments of Cardiovascular Surgery and Paediatrics, Saiseikai Utsunomiya Hospital,
Utsunomiya, Tochigi, Japan

Kiso, I., Itoh, T., Morishita, M., Kato, K., and Ishikura, Y. (1978). Thorax, 33, 253-256. Blood flow and pressure measurements of right coronary artery to left ventricle fistula. A case of a dilated and tortuous right coronary artery to left ventricle fistula was surgically repaired. Preoperative intracoronary pressure measurements showed a sudden depression of diastolic pressure in the terminal part of the right coronary artery. Intraoperative mean right coronary flow was recorded as $315 \mathrm{ml} / \mathrm{min}$. After repair of the fistula, blood flow measurements showed only $35 \mathrm{ml} / \mathrm{min}$, which suggested that a large amount of blood was stolen by the fistula. Although systolic and diastolic murmurs only were heard in our patient, continuous murmurs have been noticed by some observers. From a study of the preoperative physical findings, intraoperative coronary flow measurements, and other operative findings, the genesis of heart murmurs relating to this type of anomaly is discussed.

To date, more than 250 cases of coronary artery fistula have been reported, but communications with the left ventricle or atrium are rare.

This paper reports a case of a dilated and tortuous right coronary artery which communicated with the left ventricle. Intracoronary pressure measurements and operative flow measurements were obtained before and after surgical correction. The heart murmurs related to this type of anomaly are analysed and discussed.

\section{Case report}

A 4-year-old girl was referred to the Saiseikai Utsunomiya Hospital on 31 January 1977 for evaluation of a murmur which had first been recognised at 3 years of age. Physical examination revealed a well-developed, well-nourished girl. She had no symptoms. Pulse rate was 88 per minute and regular. Blood pressure was $100 / 60 \mathrm{mmHg}$. No cyanosis or clubbing was observed. No thrills were palpable. A grade 3/6 diastolic murmur was heard in the fourth intercostal space at the right sternal border. A grade 2/6 systolic ejection murmur was noticed at the mid left sternal border. A phonocardiogram confirmed these observations. An electrocardiogram showed evidence of combined ventricular hypertrophy. A chest radiograph revealed cardiomegaly with normal pulmonary vascular markings (Fig. 1). Complete right and left cardiac catheterisations with ventriculography and selective coronary angiography were performed. Haemodynamic data and oxygen saturations, listed in the Table and Fig. 2, revealed no left-to-right shunt. Right coronary angiography revealed a fistulous connection between the dilated and tortuous right coronary artery and the left ventricle .The catheter, which entered the right coronary artery easily, could not reach the left ventricle. In the proximal portion of the right coronary artery there was no significant difference between coronary artery pressure $(98 / 68 \mathrm{mmHg})$ and aortic root pressure $(100 / 72 \mathrm{mmHg})$. In the terminal part, diastolic pressure dropped suddenly $(96 / 36 \mathrm{mmHg})$, which was thought to be a reflection of the left ventricular pressure through the fistula. The course and distribution of the left coronary artery were normal.

Operation was performed on 5 May 1977. The chest was opened through a median sternotomy. The right coronary artery was $11 \mathrm{~mm}$ in external diameter and was tortuous. A diastolic thrill was palpable on the terminal part only of the right coronary artery. No systolic thrill was palpable. An electromagnetic flow probe ${ }^{1}$ was placed around the dilated main right coronary artery. Mean

${ }^{1}$ Gould Statham Automatic Clinical Blood Flowmeter, Gould, Inc, Oxnard, Calif, USA 


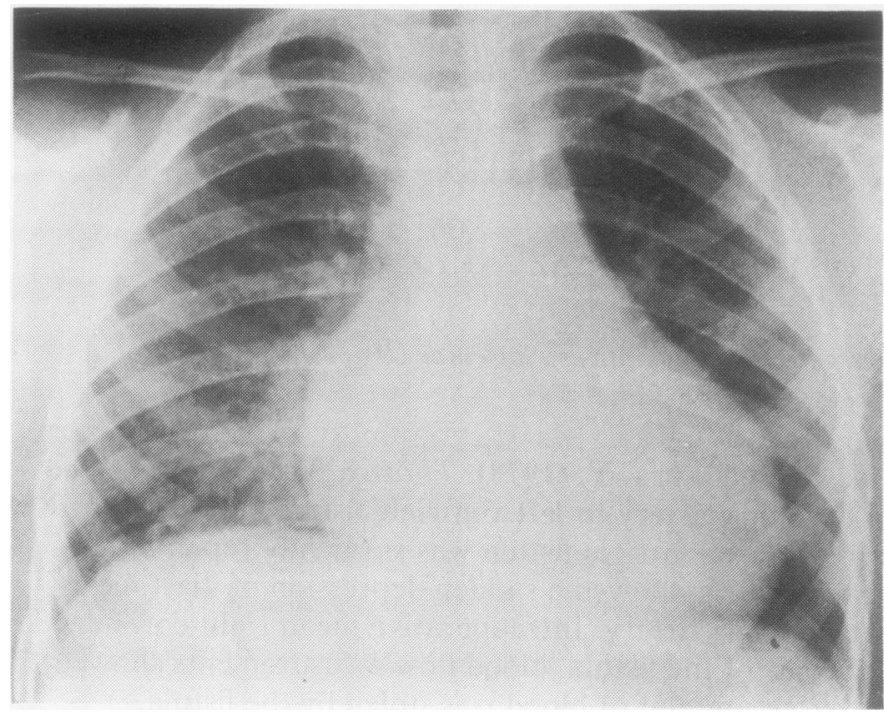

Fig. 1 Preoperative chest radiograph: cardiomegaly with normal vascular markings.

Table Preoperative cardiac catheterisation data

\begin{tabular}{llc}
\hline & $\begin{array}{l}\text { Oxygen } \\
\text { saturation (\%) }\end{array}$ & $\begin{array}{l}\text { Pressure (mmHg) } \\
\text { Max/Min (mean) }\end{array}$ \\
\hline Superior vena cava & 79 & $8 / 2(6)$ \\
Inferior vena cava & 77 & $7 / 5(6)$ \\
Right atrium (medial) & 78 & $7 / 3(6)$ \\
Right atrium (lateral) & 76 & $7 / 3(6)$ \\
Right ventricle (inflow) & 76 & $24 / 2(11)$ \\
Right ventricle (outflow) & 74 & $24 / 2(11)$ \\
Pulmonary artery (main) & 78 & $24 / 12(16)$ \\
Pulmonary artery (left) & 78 & $20 / 10(14)$ \\
Left ventricle & 91 & $104 / 6(54)$ \\
Ascending aorta & & $104 / 68(88)$ \\
\hline
\end{tabular}

blood flow was recorded as $315 \mathrm{ml} / \mathrm{min}$. Retrograde flow during systole was noted (Fig. 3).

Under cardiopulmonary bypass, a coronary arteriotomy was performed opposite the fistulous opening. The stoma of the fistula, which was located just distal to the posterior descending branch of the right coronary artery, measured about $5 \mathrm{~mm}$ in diameter. The communication with the left ventricular cavity was closed with interrupted mattress sutures (Symbas et al., 1967). After weaning from cardiopulmonary bypass, no electrocardiographic abnormalities were noted and the thrill over the previously fistulous area was no longer present. The mean right coronary flow was $35 \mathrm{ml} / \mathrm{min}$ (Fig. 4). The tracing still showed retrograde flow during systole, as is normally seen in the left coronary artery wave form. The patient made an uneventful recovery and no heart murmurs were heard.

\section{Discussion}

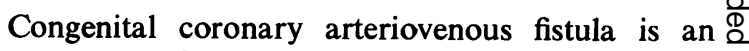
uncommon form of congenital heart disease. The $\overrightarrow{\vec{O}}$ most common type of coronary arteriovenous 3 fistula is between the right coronary artery and a low-pressure cardiac chamber. Blood flow from the coronary artery into the low-pressure chamber occurs in both systole and diastole, resulting in a continuous murmur.

The anomalies communicating with the left $\frac{0}{7}$ ventricle are rare. An excellent review of congenital coronary artery fistula communicating with the left ventricle has been published by Muraki et al. (1975). Of the 15 cases reviewed by 윽 these authors, a 'to and fro' murmur was present $\supset$ in seven, a diastolic murmur only in five, and a continuous murmur in two cases (McNamara and N Gross, 1969; de Nef et al., 1971). Theoretically, a continuous murmur should not be heard in this $N$ type of anomaly. During diastole the pressure in $\mathrm{W}$ the left ventricle is less than in the aorta, and the heart muscle is relaxed, resulting in coronary $\varrho$ blood flow towards the left ventricle. On the other $\mathbb{\varnothing}$ hand, during systole the left ventricular pressure $\stackrel{\mathscr{S}}{?}$ is a little higher than the pressure in the coronary $T$ artery, resulting in reversed blood flow towards the coronary artery from the left ventricle. There- $\triangle$ fore a 'to and fro' murmur might be audible $\mathbb{Q}$ rather than a continuous murmur.

Eguchi et al. (1970) thought that the systolic 8 murmur seen in this type of arteriovenous fistula was due to the systolic ejection of blood from 


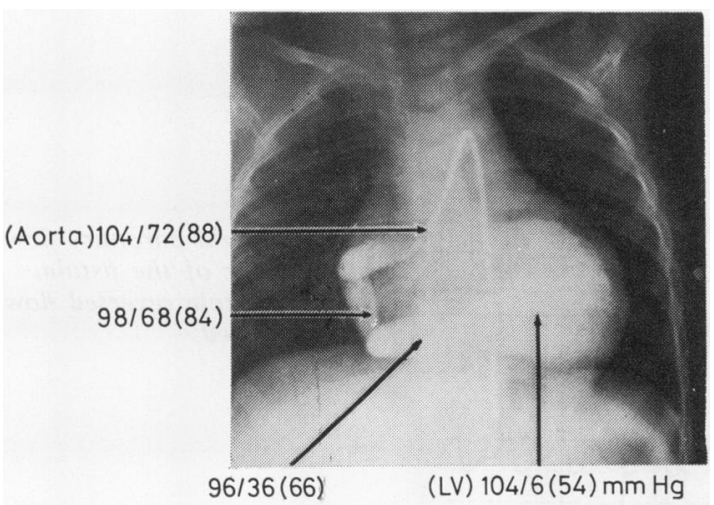

(a)

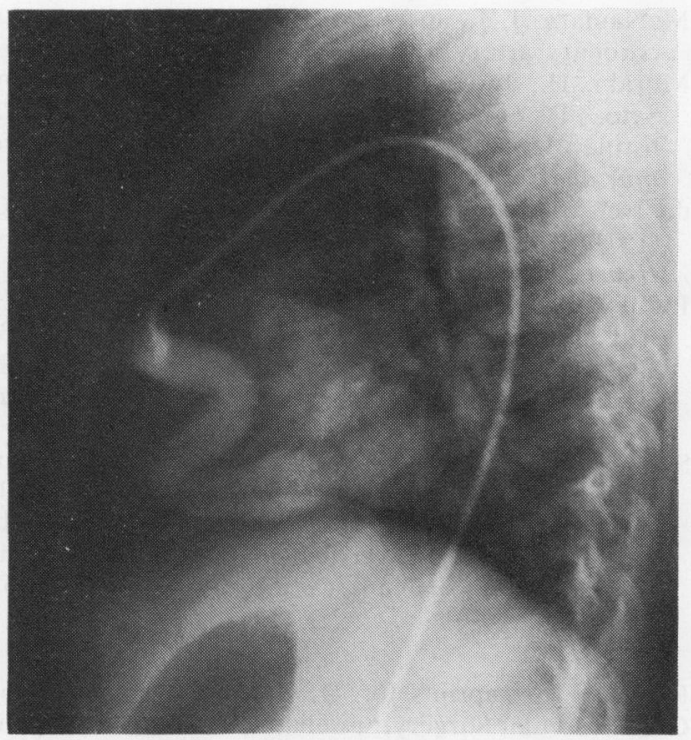

(b)

Fig. 2 Right coronary angiogram and pressure measurements (a) anteroposterior projection; (b) lateral projection. Note diastolic pressure in the terminal part of the right coronary artery was lower than in the aortic root. the left ventricle into the coronary artery through a large fistula, and that a fistula with a small stoma would not open during ventricular contraction. However, in our patient the left ventriculogram revealed no contrast substance in the coronary artery during systole and no thrill was palpable during systole over the right coronary artery. However, the stoma appeared to be large and it was seen to be open during systole through the coronary arteriotomy while the heart was still beating just after aortic cross-clamping.

Although the flow meter showed retrograde flow in the main right coronary artery during systole before the repair of the fistula, we could not say whether or not blood was ejected from the left ventricle to the coronary artery. After the repair of the arteriovenous fistula there was still retrograde flow in systole in the right coronary artery, as is usually seen in the left coronary wave form. It is suspected that the systolic phase is too short to allow ejection of blood from the left ventricle into the coronary artery after a diastolic phase during which a large amount of blood has flowed towards the left ventricle. This theory would correlate with the observation that there was no systolic murmur at the area where the diastolic murmur was heard loudest. A systolic murmur in the left mid-precordial area should be due to systolic ejection from the left ventricle to the aorta from the increased blood flow, as Gasul et al. (1960) suggested.

In congenital coronary arteriovenous fistulae, the systolic murmur has been attributed to the tortuosity or aneurysmal dilatation of the coronary artery. This idea has been dismissed (Muraki et al., 1975) because, although the tortuosity had not been corrected immediately after the repair of the fistula, the heart murmur was no longer present in any case reported.

Very few studies of the phasic flow of blood through a coronary artery fistula have been reported (Phillips et al., 1973). In our patient the flow pattern around the stoma of the fistula could not be obtained because of inadequate access. However, blood measurements in the main right

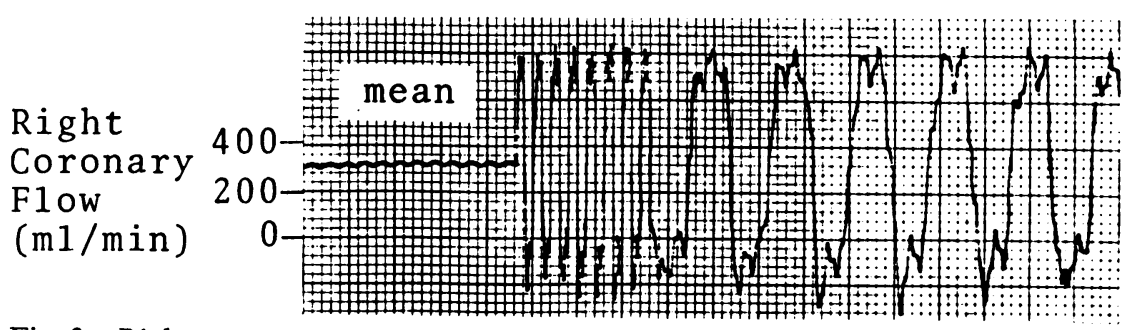

Fig. 3 Right coronary flow before the repair of the fistula. 


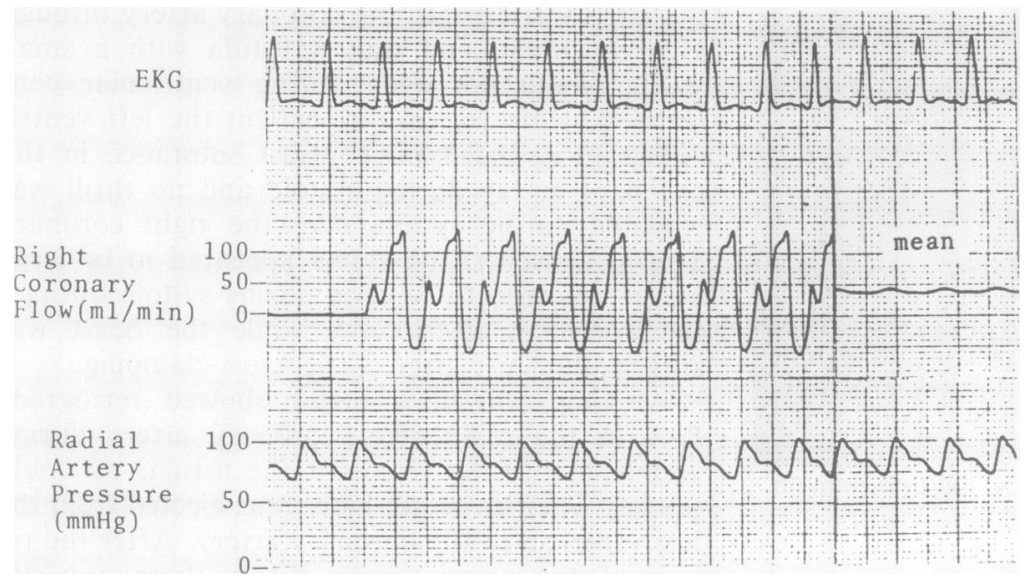

Fig. 4 Right coronary flow $\vec{\circ}$ after repair of the fistula. During systole reversed flow was observed.

coronary artery before and after the repair of the fistula showed that a large amount of blood was stolen from the aorta by the fistula, a situation which resembled aortic regurgitation haemodynamically. In our patient, the amount of regurgitation was suspected to be around $280 \mathrm{ml} / \mathrm{min}$, which might correspond to more than $20 \%$ of the cardiac output. This 'steal' phenomenon may cause reduced perfusion of the myocardium. Fortunately, there was no electrocardiographic change suggesting myocardial ischaemia before operation in our patient.

\section{References}

Eguchi, S., Nitta, H., Asano, K., Tanaka, M., and Hoshino, K. (1970). Congenital fistula of the right coronary artery to the left ventricle. American Heart Journal, 80, 242-246.

Gasul, B. M., Arcilla, R. A., Fell, E. H., Lynfield, J., Bicoff, J. P., and Luan, L. L. (1960). Congenital coronary arteriovenous fistula. Pediatrics, 25, 531560.
McNamara, J. J., and Gross, R. E. (1969). Congenital coronary artery fistula. Surgery, 65, 59-69.

Muraki, H., Inoue, S., Kozaki, T., Uozumi, Z., and@ Sato, T. (1975). Clinical features of congenitalo fistula of coronary artery to left ventricle. Respiration and Circulation (Tokyo), 23, 431-440.

de Nef, J. J. E., Varghese, P. J., and Losekoot, G.o (1971). Congenital coronary artery fistula. British $\frac{\mathrm{Q}}{\mathrm{Q}}$ Heart Journal, 33, 857-862.

Phillips, S. J., Goodman, P., Goldfine, R., Pall, L., $\overrightarrow{\vec{O}}$ Rubenfire, M., Jaron, D., and Kantrowitz, A. (1973). 3 Blood flow measurements during repair of a right $?$ coronary artery superior vena cava fistula. Annalso of Surgery, 177, 63-65.

Symbas, P. N., Schlant, R. C., Hatcher, C. R., and Lindsay, J. (1967). Congenital fistula of right coronary artery to right ventricle complicated by. Actinobacillus actino-mycetemcomitans endarteritis. Journal of Thoracic and Cardiovascular Surgery, 53, 379-384.

Requests for reprints to: Dr. I. Kiso, Department of $\stackrel{\circ}{\triangle}$ Cardiovascular Surgery, Saiseikai Utsunomiya Hospital, $\frac{D}{2}$ Utsunomiya, Tochigi, Japan. 